\title{
Correction to: Total pancreatectomy sequelae and quality of life: results of islet autotransplantation as a possible mitigation strategy
}

\author{
Francesca Aleotti ${ }^{1} \cdot$ Rita Nano $^{2} \cdot$ Lorenzo Piemonti $^{2} \cdot$ Massimo Falconi $^{1} \cdot$ Gianpaolo Balzano $^{1}$ (i)
}

Published online: 18 August 2021

(C) Italian Society of Surgery (SIC) 2021

\section{Correction to: Updates in Surgery \\ https://doi.org/10.1007/s13304-021-01129-w}

The first and last names were swapped for all authors in Publisher's Note Springer Nature remains neutral with regard to the original publication. The correct first and last names, jurisdictional claims in published maps and institutional affiliations. respectively are provided below:

Francesca Aleotti

Rita Nano

Lorenzo Piemonti

Massimo Falconi and

Gianpaolo Balzano

The original article has been corrected.

The original article can be found online at https://doi.org/10.1007/ s13304-021-01129-w.

Gianpaolo Balzano

balzano.gianpaolo@hsr.it

1 Chirurgia del Pancreas, Pancreas Translational and Clinical Center, IRCCS Ospedale San Raffaele, Milano, Italy

2 Diabetes Research Institute, IRCCS Ospedale San Raffaele, Milano, Italy 